\title{
Cognitive Ergonomics: The Use Of Mind Mapping Tool In Maintaining Productive Sector Of A Brazilian Paper Company
}

\author{
Mattos, Diego ${ }^{\mathrm{a}}$, Mateus Junior, José Roberto ${ }^{\mathrm{a}}$ and Merino, Eugenio ${ }^{\mathrm{a}}$ \\ ${ }^{a}$ Federal University of Santa Catarina - Production Engineering Pos-Graduating Program, Brazil.
}

\begin{abstract}
The use of mind maps as a method of building knowledge, planning, organizing activities and ideas can be seen in the literature related to ergonomics. The results of such use are relevant and its use in academic area found. However, regarding to its use in industrial environments, studies can't not be found. With this scenario, and based on the perception of the ergonomist about the importance of using methods such as mind maps in support of human cognition, it seems pertinent to its use in industry sectors whose cognitive demand requires. Given these assumptions, this study aimed to apply the method of Mind Maps in Productive Maintenance sector of a Brazilian paper. The Productive Maintenance sector in the Paper Industry has an important contribution to operational performance. With practical Predictive Maintenance, Preventive Maintenance and Corrective Maintenance, the industry advocates to make the machines to produce paper is not to stop producing when they are programmed to do so. Among the practices cited, the Preventive Maintenance is one that leads to pre-determined intervals in order to reduce the possibility of placing the equipment in a condition below the required level of acceptance.
\end{abstract}

Therefore, this article aims to propose using the tool "mental maps" in order to collaborate in planning and implementation of preventive maintenance activities in the sector of mechanical maintenance of a pulp and paper industry in southern Brazil. The study investigated the maintenance sector through its employees, who went through training about the tool and then use it and ergonomists company.

Keywords: mental maps. preventive maintenance. Cognitive ergonomics.

\section{Introduction}

The cognitive load is now the object of several studies in the area of ergonomics. It can be highlighted as a risk factor, because in some activities requiring mental and information overload can induce the man to errors and fatigue. The ability to keep information is limited. George A. Miller was studying in 1956 the human cognitive limitations.

"Studies published by George Miller in 1956, referred to a "magic number" $7 \pm 2$. On which the human cognitive system can handle only a limited amount of information ranging from 5 to 9 items at a time, ie, it is possible to assimilate, in a natural and satisfactory, five to nine pieces of information at a time. Once exceeded these limits, reasoning and learning are below the expected performance, overloading the cognitive structure." (Santos and Tarouca, 2007).
Still according to the author:

"This theory is due to John Swell (2003), Australian psychologist, who devotes himself to the study of this theory is that by definition be a universal set of principles that result in a learning environment that is efficient and therefore promote an increase in process capability of human cognition. Principles which aims to make human interaction with technology more in line with the cognitive process." (Santos and Tarouca, 2007).

"The learning takes place so better when the information process is aligned with the human cognitive process, ie when the volume of information offered to the student is compatible with the capacity of human understanding. So the Cognitive Load Theory, is based on natural human inability to process lots of information in memory each time." (Swell, 2003). 
The sector of mechanical maintenance performs a variety of major industries with demanding mental activities. The preventive maintenance shutdowns among these activities are highlighted because they require time-limited actions involve various workers from different specialties, and almost always requires the completion of a large number of these professional services. Communication can be a factor causing failures as well as information overload in such practices as cited.

This work, a case study, aims to bring the introduction of a tool for organizing ideas called mind maps as a means to meet this significant demand within the cognitive ergonomics, applied to a paper mill and packaging in the city of Bonita Vargem, Brazil.

The sector chosen for the application of the tool was maintenance mechanics, with emphasis on preventive maintenance practices, where there is a great need for storing and sharing information quickly and conveniently in order to optimize the time and carry out activities with a small margin of error and accidents.

The importance of ergonomics work under this work justifies this cognitive perspective.

As the worker and the manufacturing work system interact to accomplish its task successfully, will have better results. For this he needs to know to access their resources: Visual, auditory and body to use them properly, and allow a self-identity. Activity how to receive information from other people, decide what actions are appropriate to carry out these actions and transmit information to others so they can perform their tasks are objective study of psychological or cognitive ergonomics (Canas and WAERN, 2001).

\subsection{Cognitive Ergonomics}

According to Cognitive Ergonomics \& Waerns Cañas (2001) "intends to analyze the cognitive processes involved in the interaction: the memory (operating and long term), the processes of decision making, attention (mental load and consciousness), and finally the structures and processes to perceive, store and retrieve information." "The Cognitive Ergonomics is not intended to theorize about human cognition, its role is to match the technological characteristics and needs of its users" \& Marmahas Kontogiannis (2001). "For this, she seeks to understand cognition in a situated and purposive, that is, within a specific context of action-oriented and to achieve a goal" (Sarmet, 2003).

This study aimed to bring the introduction of a tool for organizing ideas called mind maps as an important means of meeting demand within the cognitive ergonomics, in a paper mill and packing in the city of Vargem Bonita, Brazil.

The sector chosen for the application of the tool was maintenance, with emphasis on preventive maintenance practices, where there is a great need for storing and sharing information quickly and conveniently in order to optimize the time and carry out activities with a small margin of error and accidents.

The importance of ergonomics work under this cognitive perspectives justifies this work.

"As an employee of manufacturing and work system interact to accomplish their task successfully, Teramo best results. For this he needs to know its resources to access: Visual, audtivo body and uses them to appropriate respect, and allow a self-identity. Activities such as receiving information from other people, decide what actions are appropriate to carry out these actions and transmit information to other people so they can perform their tasks are objective study of psychological or cognitive ergonomics "(Canas and Waern, 2001).

\section{Theoretical}

\subsection{Human Cognition}

Human cognition is the process of storing information, to promote learning. Through it we gain new knowledge and can use them as our personal demand.

When it comes to learning, it is necessary to do some reading on prior research results and developed by Piaget.

These reflections are essential to understanding the development of skills, or the mental connections, assuming that learning occurs when this balance and dialogue between subject and environment. Thus, the subject tends to adapt to the environment through interactions with him (Gil, Smith, Rizzo, Brandão, 2001). 
Also according to the authors, "the adaptation to the environment involves a balance between two processes complement each other, and which take place almost simultaneously in thought: accommodation and assimilation" (Gil, Smith, Rizzo, Brandão, 2001).

All conduct is given to an assimilation of earlier schemes (assimilation schemes inherited the varying degrees of depth) and all conduct is at the same time, accommodation of these schemes to the current situation. It follows that the theory of development calls necessarily for the notion of balance, because all conduct tends to ensure balance between the internal and external factors or, more generally, between assimilation and accommodation (Piaget, 1998).

Weill-Fassina (1990) includes "cognitive aspects as being made up of operational modes of action sequences, gestures, probate search and information processing, communications, verbal or graphic IDs incidents or disturbances that characterize the task performed by the actual person."

\subsection{Cognitive Ergonomics}

Cognitive Ergonomics According Waerns \& Cañas (2001) "aims to examine the cognitive processes involved in the interaction: the memory (operating and long term), the processes of decision making, attention (mental load and consciousness), and finally the structures and processes to perceive, store and retrieve information." "The Cognitive Ergonomics is not intended to theorize about human cognition, its role is to match the technological characteristics and needs of their users" \& Marmahas Kontogiannis (2001). "For this, she seeks to understand cognition and situated in a purposive, ie, within a specific context of action-oriented and to achieve a goal" (Sarmet, 2003).

\subsection{Mind Map}

"Mental map or memograma is a tool for organizing ideas using key words, colors and images in a structure that radiates from a center. The drawings of mental maps favor learning and, consequently, improve personal productivity "(Tribol, 2004).

According to the author, the concept of mental map was developed by Tony Buzan in London in the last decade of 70. It is estimated that this tool is used by more than 100 million people in the different continents.

According to Vilela (2002), "the benefit of greater impact achieved by regular use of mind maps is to improve the structure of thought:" We are accustomed to linear ways of thinking "in a model of cause and effect."

"The contact with mental maps teaches the structure of thought called radiant, based on possibilities, alternatives, multiple aspects, levels. Changing the thinking at this level significantly impacts the ability of the person, leading to the skills and mental models richer and thus enriching and perfecting their choices. Since we are choosing every moment even if not aware of it, our quality of life ends up being affected the first inside, and reflecting the outside - for the better. (Vilela, 2002).

In Figure 1 we have a mental map as a blueprint for exmplo.

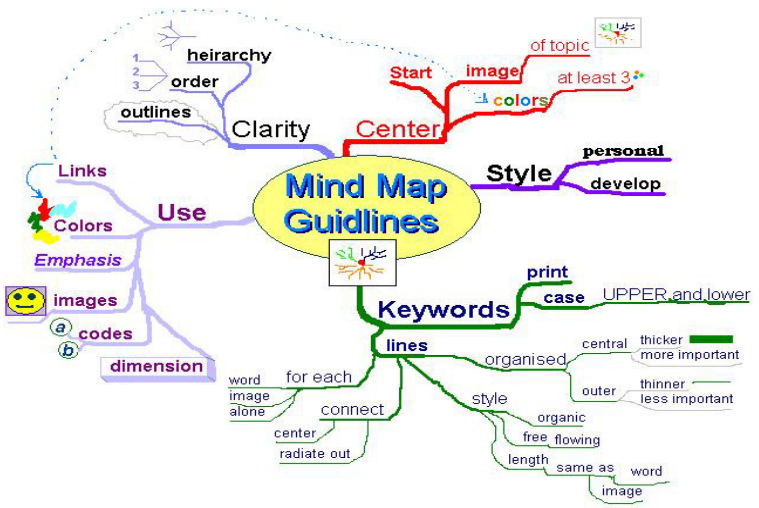

Figure 1: Scheme for mental map

\subsection{Preventive Maintenance}

The Productive Maintenance sector in the paper industry has an important contribution to operational performance. With practical Predictive Maintenance, Preventive Maintenance and Corrective Maintenance, the industry advocates to make the machines to produce paper is not to stop producing when they are programmed to do so. Among the practices cited, the Preventive Maintenance is one that leads to predetermined intervals in order to reduce the possibility of placing the equipment in a condition below the required level of acceptance. This maintenance can be based on time intervals pre-determined and / or predetermined operating conditions, and may also require, for its execution the equipment is 
decommissioned. SOTHARD (1996) notes that "involves preventive maintenance on equipment and routine care includes lubrication of machines and spare parts intensive wear." Adds that "preventive maintenance alone does not provide conditions for further prediction of component failure or how to avoid effects on production". The author also mentions that "the predictive maintenance reviews the past performance to predict when a particular component will fail." SOTHARD (1996) also exemplifies that "the maintenance can opt for an exchange of components every 360 hours of use, changing the play prematurely to avoid arrest."

\section{Methodology}

This study aimed to propose solutions through the tool "mind maps" for purposes of facilitating the distribution and processing of information in the field of mechanical maintenance of a pulp company in the state of Santa Catarina. It and a Case Study. Study participants were the maintenance sector through its employees, who underwent a training on the tool then use it in practice and within the context of the situation, and ergonomists responsible for the company, providing training and consulting. The cognitive demand in the maintenance sector proves to be important because there is a great need in the process of storing and distributing information about the division of tasks and responsibilities during the stops for avoidance of paper machines. The proposal of using the tool "mind maps" responds to this demand, seeking to meet the individual and collective difficulties with regard to the availability of this information, both qualitatively and quantitatively, simply assisting in the fluency and the personal cognitive process.

\subsection{Location}

The study was applied and analyzed in the field of mechanical maintenance of a paper industry in the city of Vargem Bonita, Santa Catarina, Brazil.

\subsection{Sample}

Study participants were the maintenance sector through its employees a total of four programmers over the engineer in the industry, which underwent a training on the tool then use it in practice and within the context of the situation, and ergonomists responsible for the company, providing training and consulting.

\subsection{Materials and Procedures}

Through a training using Power Point, videos and hands-on activities about human cognition and cognitive ergonomics was presented and indicated the tool of mental maps as an alternative to support this demand for information.

After training, employees were encouraged to organize themselves to put into practice the concept of mental maps. After that, in a joint work, we designed a mental map to guide and lay the machine stops for preventive maintenance as scheduled.

\section{Results}

The immediate result of the training is to mount a mental map with the collaboration of all programmers in a box in the meeting room of the sector. The reference map was designed to stop the machine of the month of May 2011. Would be four paper machines and a boiler stops, which creates a renewed effort in the maintenance sector of the cognitive point of view. The risk of errors and accidents is high in view of the complexity of machines and operations to be performed around processes stop.

In this mental map each developer was responsible for his business. Each branch had a specific task and its variations. We used different colors to facilitate cognition and storage of information contained therein. Figure 2 shows a picture of the mental map constructed after the training:

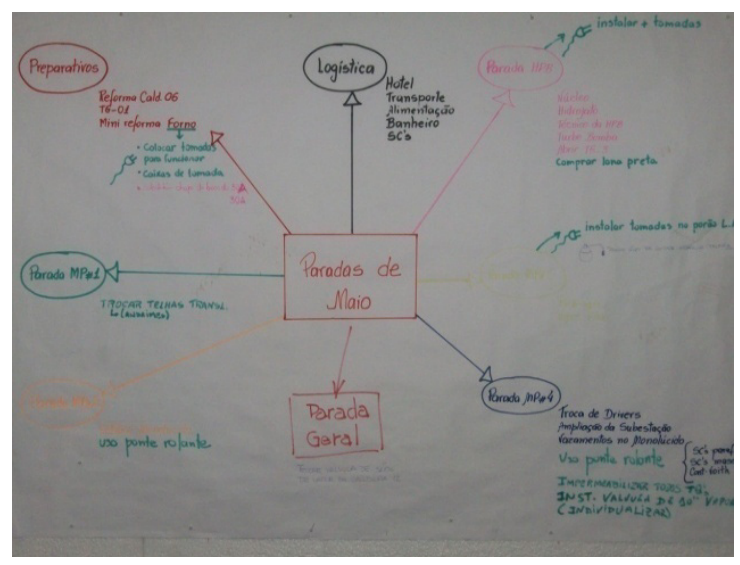

Figure 2: Map of mental avoidance stop the month of May.

The central theme of the mental map mentioned "stops in May," which refers to the month a greater number of machine downtime for preventive 
maintenance. The ramifications of each bring a specific topic relevant to the operation. In Figure 3 we have the central theme of the map:

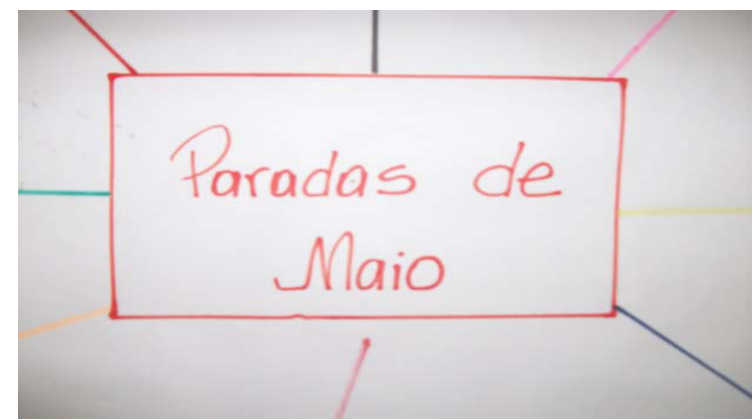

Figure 3: central theme.

Clockwise branches have to:

Stop-HPB refers to the boiler HPB, and brings in its sub-branches details regarding: installing outlets, buy black canvas, open T6-3, Nuclear Bomb, among others. Photo in Figure 4:

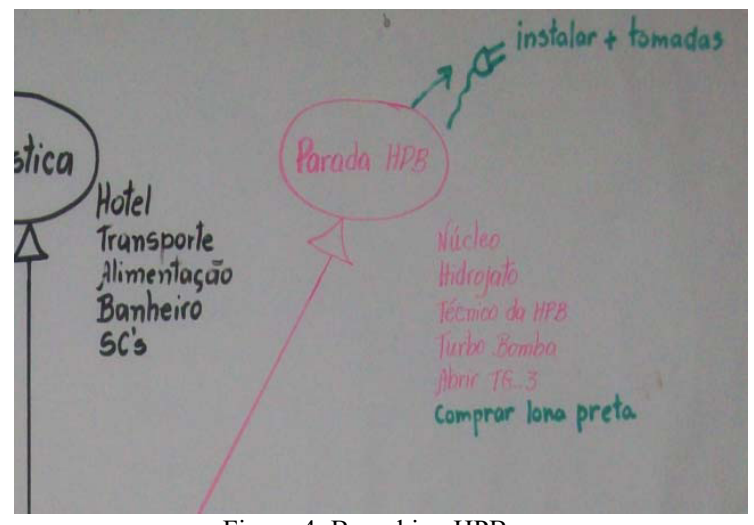

Figure 4: Branching HPB

- Stop 5 MP: Refers to the paper machine 5. If subbranches into: change the oil of the hydraulic unit of the sacks, install outlets in the basement, among others. Photo figura5 in:

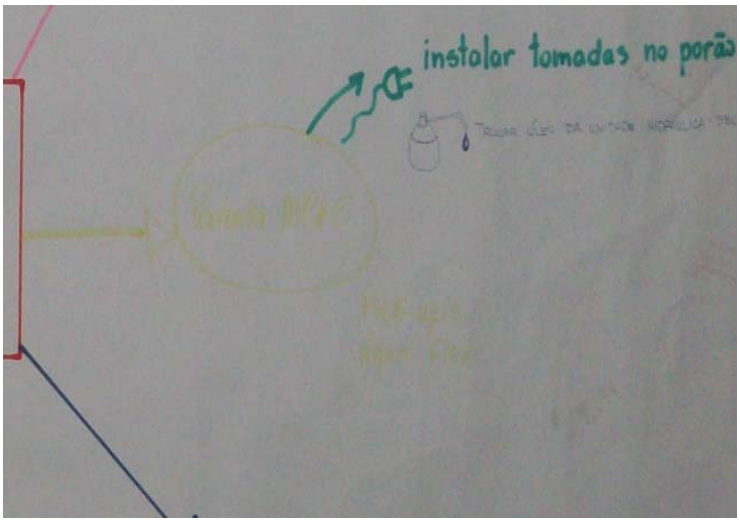

Figure 5: Branch to stop the paper machine 5.

- Stop MP4: refers to the paper machine 4. If subbranches into: exchange of drivers, expanding the substation, in monolucid leaks, using crane, among others. Photo in Figure 6:

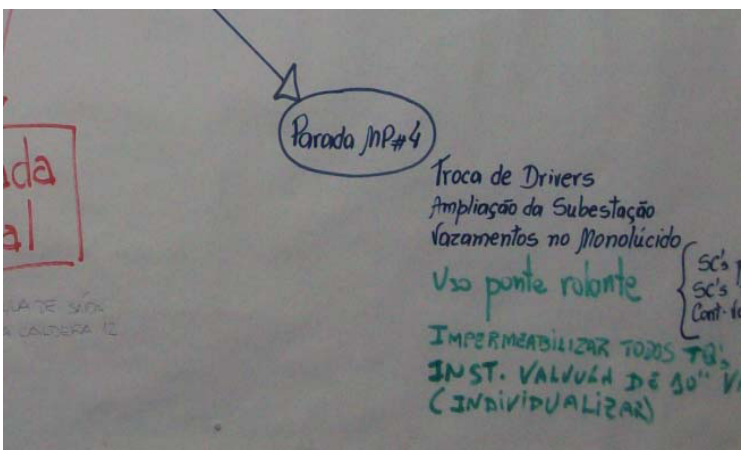

Figure 6: Branch to stop the paper machine 4.

- Parade General refers to the parade in general and sub-branches into: replace the air outlet valve of the boiler. Photo in Figure 7:

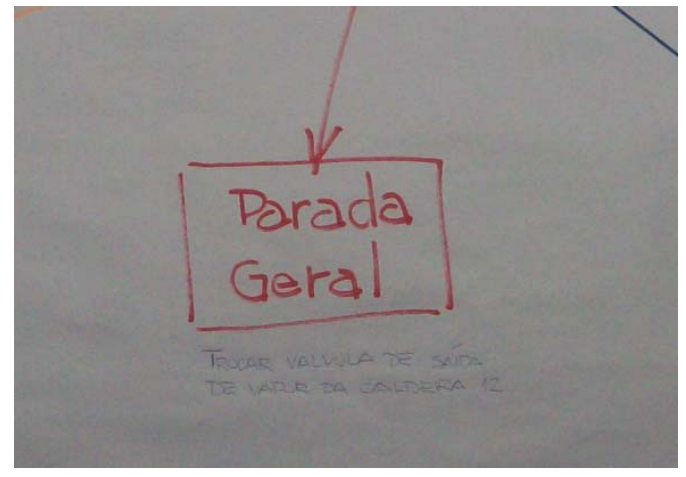

Figure 7: Branching general shutdown of machine.

- Stop 2 MP: refers to the paper machine 2, and subbranches into: monolucid grinding and use of the crane. Photo in Figure 8: 


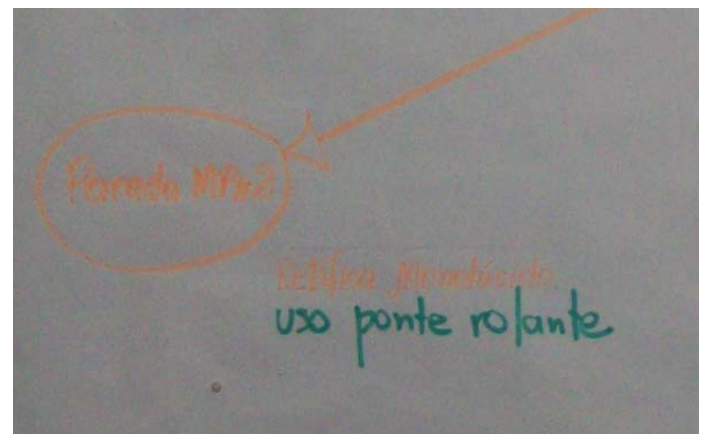

Figure 8: Branch to stop the paper machine 2.

- Stop MP1: refers to a paper machine, and subbranches into: swap tiles cross, which in turn subdivides into "scaffolds". Photo in Figure 9:

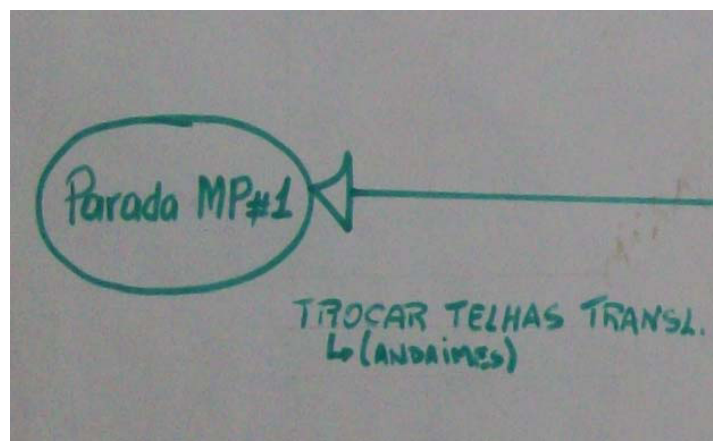

Figure 9: Branch to stop a paper machine.

-Preparation refers to the preparation before the machines stop. If sub-branches into: reform of the Caldera 06, TG-01, mini-oven reform which in turn is sub-branches into: to operate light switches, outlet box, replace the base plate 30A. Photo Figure 10:

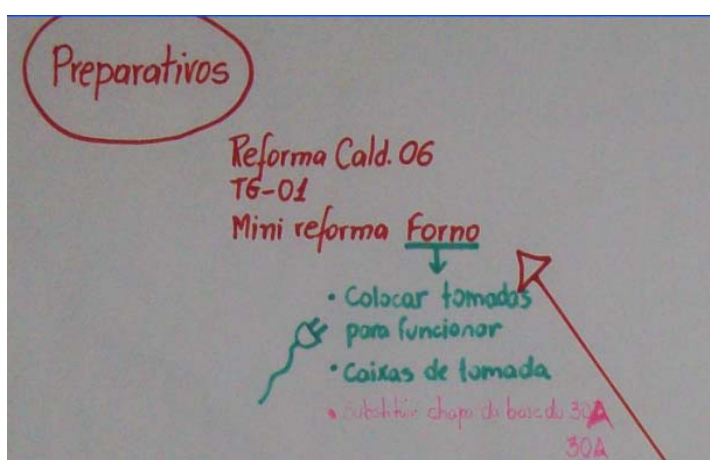

Figure 10: Branch to prepare the paper machine downtime.

- Logistics: Refers to the process of entry, exit and stay of permanent employees and contractors to carry out preventive stops. If sub-branches into: hotel, transportation, food, bathrooms, SC's. Photo in Figure 11:

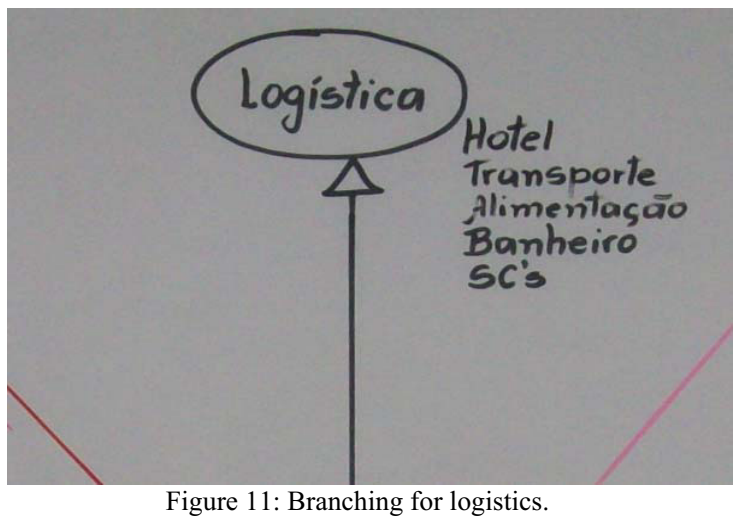

\section{Conclusion}

After weeks of downtime and the use of preventive mental map as a tool for organizing ideas, employees responsible for maintaining manufacturing sector reported extreme value and functionality of the tool. According to reports, the mental map facilitated communication sector, and have an impact on the organization of tasks and retention of employees by business.

After a week of preventive maintenance work that involved an estimated 300 workers, more than half of sub-contractors, according to the company SESMT there were only three accidents considered light, which can be considered a low incidence.

The study shows the importance of memorizing and organizing tool to facilitate communication and cognition. It also shows that the tool known as mental maps can be of great value to the industries that use the operation of preventive maintenance as part of its procedures in view of the low number of accidents and good acceptance and belief of the developers.

Further studies about this tool and addressing the practice of preventive maintenance are needed to consolidate more and more the idea of the organization and the importance that should be given to human cognition, thereby enhancing a tool that enables an ergonomic intervention in terms of cognitive, often underestimated by health professionals. 
References

MARMARAS N. KONTOGIANIS \& T. (2001). Cognitive Task. In: G. Salvendy, Handbook of Industrial Engineering. New York: John Wiley \& Sons.

CAÑAS, J.J. \& WAERS, Y. (2001). Cognitive Ergonomics - Psychological Aspects de la interacción de las personas con la de la Información Technology. Ed Medica Panamericana.

SARMET, M.M. (2003). Ergonomic Analysis of complex cognitive tasks mediated by technological apparatus. Unpublished dissertation submitted to the Institute of Psychology, University of Brasilia. UnB, Brasília.

Weill-Fassina, A. (1990). Analysis of the Cognitive Aspects of Labor. Translation of the Introduction of the book "Les Analyses du Travail. Formes et Engeux. Cerea: Paris. No. 54:193-198. Pedagogic text of the Laboratory of Ergonomics - PST / IP / UnB. 123

Gil, G. , Silva, M. B. C. C. , Rizzo, R. L. ; Brandão, S. F. M. The model of knowledge representation in the form of conceptual maps; 2001

Piaget, Jean. Thinkers. Cultural April, 1983

Piaget, Jean. Six psychological studies. Trad. Maria Alice M. D'Amorim and Paulo Sergio L. Silva. 23rd ed. Rio de Janeiro, Forense Universitária, 1998.

Vilela, V. V. Introduction to mental mapams: a tool for organizing, learning and productivity. November, 2002.

SWELLER, John. Cognitive Load Theory: A Special Issue of educational Psychologist". LEA, Inc, 2003. SWELLER, J; MERRIENBOER, J. Cognitive Load Theory and Complex Learning.

SANTOS, L. M. A; TAROUCO, L. M. R; A importância do estudo da teoria da carga cognitiva em uma educação tecnológica. PGIE/UFRGS, 2007.
E. P. R. Tribol; mental maps: an introduction; Sao Caetano do Sul, in August 2004. Available at: http://professor.ucg.br/siteDocente/admin/arquivosUp load/13286/material/Mapas_mentais.pdfhttp://profess or.ucg.br/siteDocente/admin/arquivosUpload/13286/ material/Mapas_mentais.pdfhttp://professor.ucg.br/sit eDocente/admin/arquivosUpload/13286/material/Map as_mentais.pdf 